\title{
Phycobilisome isolation and C-phycocyanin purification from the cyanobacterium Aphanizomenon gracile
}

\author{
R. PIRON*, T. BUSTAMANTE* ${ }^{*}$ A. BARRIGA**, and N. LAGOS*,+ \\ Membrane Biochemistry Laboratory, Department of Physiology and Biophysics, Faculty of Medicine, \\ University of Chile, Independencia 1027, 8380000 Santiago, Chile* \\ Mass Spectrometry Unit, Faculty of Chemical and Pharmaceutical Sciences, University of Chile, \\ Santos Dumont 964, 8380494 Santiago, Chile ** $^{*}$
}

\begin{abstract}
Cyanobacterial phycobilisomes are made up from phycobiliproteins held together by linker proteins. Incident photons are absorbed by the phycobiliproteins that carry linear tetrapyrrole chromophores with extended conjugated bond systems. The chemical structure of the chromophores also bestows the phycobiliproteins with excellent radical scavenging and antioxidant properties and phycobiliproteins have pharmaceutical value as such. We purified and characterized the phycobilisome and its major protein constituent C-phycocyanin from the freshwater filamentous cyanobacterium Aphanizomenon gracile. Isolated phycobilisomes were shown to be intact and contained the phycobiliproteins allophycocyanin and C-phycocyanin, but not phycoerythrin, together with the classic set of linker proteins. C-phycocyanin could be easily purified and was of analytical grade with spectral characteristics similar to that of other cyanobacterial species. To our best knowledge, this is the first study to report the purification and characterization of the Aphanizomenon gracile phycobilisome and C-phycocyanin.
\end{abstract}

Additional key words: mass spectrometry; protein chromatography; protein cross-linking.

\section{Introduction}

Cyanobacteria were among the first oxygen-producing organisms on our planet when 3 billion years ago these developed oxygen-evolving photosynthesis (Singh et al. 2015), the molecular mechanism by which light energy is captured and converted to the chemical energy that is used to drive cellular metabolism (Blankenship 2017). During this process, water molecules are split to generate reducing power and ATP, while releasing oxygen as a byproduct (Rexroth et al. 2017). Even today cyanobacteria still considerably contribute to molecular oxygen in our atmosphere due to their widespread distribution in aquatic and terrestrial habitats where they are often primary producers (Rexroth et al. 2017).

Cyanobacteria share the mechanism of oxygen-evolving photosynthesis with higher plants, although their molecular machinery differs. In cyanobacteria, light harvesting through chlorophyll (Chl)-protein complexes is complemented with a second type of light-harvesting antennae known as the 'phycobilisome' (PBS) (Ledermann et al. 2017). These are designed to maximally absorb across the light wavebands of the spectrum $(490-650 \mathrm{~nm})$ where Chl-based antennae absorb minimally and thus allow cyanobacteria to make efficient use of all light available in their habitat (Watanabe and Ikeuchi 2013).

Phycobilisomes (PBSs) are soluble protein structures of several megadaltons that are present on the outside of the photosynthetic membranes and are loosely associated with the membrane-embedded PSI and PSII (Liu et al. 2013, Chang et al. 2015). They are highly organized with a central core consisting of two to five parallel cylinders supporting a number of protruding cylindrical rods that serve as light-harvesting antennae and funnel captured photons to the central core (Ducret et al. 1996, Singh et al. 2015). From here, the photons are passed to reaction center Chls in both photosystems where the conversion to chemical energy takes place.

Photons are captured in the PBS by the 'phycobiliproteins', a group of brilliantly colored red or blue proteins

\footnotetext{
Received 14 August 2018, accepted 5 December 2018.

${ }^{+}$Corresponding author; phone: +56 22978 6309, e-mail: nlagos@med.uchile.cl

Abbreviations: APC - allophycocyanin; CHCA - $\alpha$-cyano-4-hydroxycinnamic acid; CPC - C-phycocyanin; Emmax - fluorescence emission maximum; FNR - ferredoxin NADP ${ }^{+}$reductase; $\mathrm{L}_{\mathrm{C}}-$ core linker protein; $\mathrm{L}_{\mathrm{CM}}-$ core-membrane linker protein; $\mathrm{L}_{\mathrm{R}}-$ rod linker protein; $\mathrm{L}_{\mathrm{RC}}$ - rod-core linker protein; $\mathrm{L}_{\mathrm{T}}$ - rod-terminal linker protein; MALDI-TOF MS - matrix-assisted laser desorption/ionization time-of-flight mass spectrometry; MW - molecular mass marker; PBS - phycobilisome; -PMF - peptide mass fingerprinting; RFU relative fluorescence units; $\lambda_{\max }-$ absorption maximum.

Acknowledgements: This work was supported by the FONDECYT Grant No. 1130037 sponsored by the Chilean Government. The authors would like to express their gratitude to Carolina Gallegos for maintenance of the cell cultures used in this study, to Camilo Recabarren for providing the micrographs of $A$. gracile, and to the remaining staff of the Membrane Biochemistry Laboratory for their critical suggestions and invaluable support. Disuccinimidyl suberate protein cross linker was a kind gift of Dr. Edio Maldonado.
} 
with a similar, conserved, globular fold that carry tetrapyrrole chains as prosthetic groups, which function as chromophores (Ledermann et al. 2017). These tetrapyrroles are covalently bound to the apoprotein via one or two thioether bonds and only differ in the number of conjugated bonds they carry (Stadnichuk 1995). This bestows them and the holoproteins to which they are attached with unique spectral properties. Depending on their absorption maxima cyanobacterial phycobiliproteins can be divided in three groups: the phycoerythrins $\left(\lambda_{\max }=\right.$ $540-570 \mathrm{~nm})$, C-phycocyanins $\left(\lambda_{\max }=610-620 \mathrm{~nm}\right)$, and allophycocyanins $\left(\lambda_{\max }=650-655 \mathrm{~nm}\right)$ (Bryant et al. 1976 , MacColl 1998, Singh et al. 2015).

All phycobiliproteins consist of alpha and beta polypeptides that associate into alpha-beta heterodimers, further conveniently referred to as $(\alpha \beta)$ monomers that are then organized in higher order structures. Monomers are arranged in trimeric $(\alpha \beta)_{3}$ ring-like structures with a central cavity that are stacked face-to-face to form hexameric $(\alpha \beta)_{6}$ discs, the building blocks from which the core and rod cylinders are made (Chang et al. 2015). The phycobilisome superstructure is held together by a second set of proteins known as the 'linker proteins' that occupy the central cavity of the phycobiliprotein discs (de Marsac and Cohen-Bazire 1977, MacColl 1998). These govern rod and core cylinder structure, anchor the phycobilisome to the photosystems, and serve as terminal acceptors that transfer the light energy from the PBS to the photosystem Chls (de Marsac and Cohen-Bazire 1977, Rusckowski and Zilinskas 1982, Peng et al. 2014, Chang et al. 2015). Depending on their position in the PBS the linker proteins are divided in 'rod-terminal linkers', 'rod linkers', 'rodcore linkers', 'core linkers', and 'core-membrane linkers' $\left(\mathrm{L}_{\mathrm{T}}, \mathrm{L}_{\mathrm{R}}, \mathrm{L}_{\mathrm{RC}}, \mathrm{L}_{\mathrm{C}}\right.$, and $\mathrm{L}_{\mathrm{CM}}$, respectively) (Glazer 1985, Singh et al. 2015).

A secondary consequence of the unique structure of the light-harvesting phycobiliproteins is that they show a wide variety of pharmaceutical properties, which are partially due to the excellent radical scavenging and antioxidant properties of the tetrapyrrole chromophores (Benedetti et al. 2004, 2010). For phycocyanobilin that is the chromophore of the C-phycocyanin polypeptides, it was shown that quenching of peroxyl radicals occurs via the transfer of a hydrogen atom to the radical. The electron that remains on the chromophore is then stabilized by the extended system of conjugated bonds present (Bhat and Madyastha 2000, Benedetti et al. 2010). Interest in these cyanobacterial products has been on the rise lately because of the health benefitting properties that have been attributed to the consumption of these. Special attention has been given to C-phycocyanin (CPC) that is the predominant phycobiliprotein of the PBS, which can account for up to $60 \%$ of the total protein mass of cyanobacteria (Singh et al. 2015). CPC extracted from Aphanizomenon and Arthrospira species, which have been consumed by tribesmen in Central America and Africa for centuries, is being extensively investigated. So far CPC, besides being a radical scavenger and antioxidant, has also been shown to harbor anti-inflammatory, antitumor, immune enhancing, and hepatorenal protective activity (reviewed in Liu et al. 2016, Fernandes e Silva et al. 2018) and the consumption of aqueous extracts rich in CPC has even been linked with reduction of chronic pain and mood enhancement (Scoglio et al. 2014, Jensen et al. 2016).

Because of an increased interest in cyanobacterial products with health benefiting properties, we set out to study the PBS and phycobiliproteins from the freshwater, diazotrophic cyanobacterium Aphanizomenon gracile. Under optimal conditions, this cyanobacterium can be cultivated to densities up to $1,000,000$ filaments per $\mathrm{mL}$ in aerated vessels. It grows at neutral $\mathrm{pH}$ and ambient temperature, is of freshwater origin and fixates atmospheric nitrogen; therefore, it has very little medium requirements. These characteristics make it well suited for controlled cultivation in bioreactors to produce compounds of pharmaceutical interest. Intact PBSs were isolated and analyzed to determine its protein composition and spectral characteristics. Subsequently also CPC was purified and characterized, which is the main phycobiliprotein. To our best knowledge, this is the first study to describe the isolation and characterization of the $A$. gracile PBS and CPC.

\section{Materials and methods}

Aphanizomenon gracile culture conditions: Cultures were grown in liquid Z8 medium under cool white fluorescent illumination $\left[60 \mu \mathrm{mol}\left(\right.\right.$ photon) $\mathrm{m}^{-2} \mathrm{~s}^{-1}$ ] and continuous bubbling at $20^{\circ} \mathrm{C}$. Visual inspection of cultures was done using a microscope and where necessary filaments were counted with a Neubauer chamber. A. gracile strain LMCEYA40 (Pereira et al. 2004), belongs to the order of the Nostocales and is a freshwater filamentous diazotrophic cyanobacterium whose cells can differentiate into heterocysts and akinetes (Fig. 1S, supplement). It is characterized by its solitary filaments, rounded to barrelshaped vegetative cells, intercalated, rounded and solitary heterocysts, cylindrical akinetes and elongated terminal cells (Komárek and Komárková 2006, Komárek 2013).

PBS preparation and ultracentrifugation: Cells were harvested from cultures in the exponential growth phase by filtration through a $5-\mu \mathrm{m}$ polypropylene filter disc. PBS were extracted according to Gantt et al. (1979) with some minor modification and unless stated differently all manipulations were performed at room temperature to prevent PBS dissociation. In short, $2 \mathrm{~g}$ of freshly filtered cells was washed twice with $0.75 \mathrm{M}$ potassium

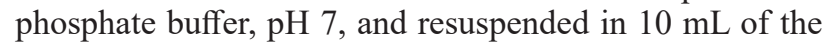
same buffer to which complete protease inhibitor tablets (Sigmafast, Sigma-Aldrich, St. Louis, MO, USA) were added according to the manufacturer's instructions. Cells were ruptured by four 15 -s cycles of sonication with a Microson ultrasonic cell disruptor (Misonix, Farmingdale, NY, USA) set at $15 \%$ intensity, Triton $X-100$ was added to a final concentration of $2-3 \%(\mathrm{v} / \mathrm{v})$ and the extracts were incubated for $30 \mathrm{~min}$ with gentle shaking. Extracts were then spun in a tabletop Sorvall MC $12 \mathrm{~V}$ centrifuge (Dupont, Wilmington, DE, USA) at 12,000 rpm for $30 \mathrm{~min}$ and the supernatant layered onto a sucrose gradient for 
ultracentrifugation. Stepwise sucrose gradients were prepared with $2 \mathrm{~mL}$ each of a $2 \mathrm{M}, 1 \mathrm{M}, 0.5 \mathrm{M}$, and $0.25 \mathrm{M}$ sucrose solution in $0.75 \mathrm{M}$ potassium phosphate buffer (pH 7). After centrifugation at $160,000 \times g$ for $180 \mathrm{~min}$ in a Sorvall $W X+$ ultracentrifuge (Thermo Scientific, Waltham, MA, USA) using a TH-660 swinging bucket rotor, PBS concentrated at the $1 \mathrm{M}$ sucrose region in a visible blue band. This band was recovered with a syringe and its buffer exchanged for $0.75 \mathrm{M}$ potassium phosphate $(\mathrm{pH} 7)$ via ultrafiltration using Pierce protein concentrators (Thermo Scientific, Waltham, MA, USA) with a $10 \mathrm{kDa}$ molecular mass cut off. PBS excitation and emission spectra were monitored with a $R F-5301 P C$ spectrofluorophotometer (Shimadzu, Kyoto, Japan) and an Epoc spectrophotometer (BioTek, Winooski, VT, USA) was used to measure absorbance and absorption spectra. Where necessary, samples were stored at $-20^{\circ} \mathrm{C}$ for further analysis.

CPC purification and SDS-PAGE: Four consecutive cycles of freezing at $-20^{\circ} \mathrm{C}$, thawing at room temperature and sonication in a Bransonic 220 sonication bath (Branson, Lawrenceville, GA, USA) for $5 \mathrm{~min}$ were sufficient to rupture the cells, which was monitored under a micro-scope. Cells were extracted using $25 \mathrm{mM}$ sodium acetate buffer ( $\mathrm{pH} 5$ ) (in a ratio of $2 \mathrm{v} / \mathrm{w}$ ) and centrifuged for $45 \mathrm{~min}$ at $18,000 \times \mathrm{g}$ in a Sorvall RC5 plus centrifuge (Dupont, Wilmington, DE, USA). The blue supernatant was recovered and then filtered through a MF-Millipore 0.45- $\mu \mathrm{m}$ mixed-cellulose membrane (Merck, Kenilworth, NJ, USA) and loaded onto a $5 \times 35 \mathrm{~cm}$ column packed with Bio-Gel P-2 resin (Bio-Rad, Hercules, CA, USA) for sizeexclusion chromatography. The same extraction buffer was used as the mobile phase and the column developed at $1.5 \mathrm{~mL} \mathrm{~min} \mathrm{~m}^{-1}$. Blue fractions were pooled, adjusted with $1 \mathrm{M}$ Trizma base to $\mathrm{pH} 7$ and passed through a $20 \times 1 \mathrm{~cm}$ column packed with ChromSpeed DA103 anion-exchange resin (Kaiteki Company, Mitsubishi Chemical Holdings Group, Tokio, Japan) that had been previously equilibrated with extraction buffer adjusted to $\mathrm{pH} 7$. The column was washed with 4 column volumes $(60 \mathrm{~mL})$ of the same buffer and subsequently developed with a linear 5-100 mM gradient of sodium phosphate buffer, $\mathrm{pH} 7$, for a total period of $90 \mathrm{~min}$ at a flow rate of $2 \mathrm{~mL} \mathrm{~min}^{-1}$. Fractions were collected every 2 min and elution was monitored by measurement of the absorbance at $280 \mathrm{~nm}\left(\mathrm{~A}_{280}\right)$ and the $\mathrm{CPC}$ specific absorbance at $620 \mathrm{~nm}\left(\mathrm{~A}_{620}\right)$. The bulk CPC eluted around $50 \mathrm{mM}$ sodium phosphate buffer of $\mathrm{pH} 7$.

Protein purity was further assayed by sodium dodecyl sulfate polyacrylamide gel electrophoresis (SDS-PAGE). Hereto protein samples were mixed with $5 \times$ concentrated loading buffer (10\% SDS, $10 \mathrm{mM}$ dithiothreitol, 20\% glycerol, v/v, 0.2 M Tris- $\mathrm{HCl}, \mathrm{pH} 6.8$ ) heated at $65^{\circ} \mathrm{C}$ for $10 \mathrm{~min}$ and loaded onto polyacrylamide gels that were run at $100 \mathrm{~V}$ until proteins had migrated into the gel and then at $200 \mathrm{~V}$ for further protein separation, with $25 \mathrm{mM}$ Tris- $\mathrm{HCl}, \mathrm{pH} 8.3,0.2 \mathrm{M}$ glycine, and $0.1 \%$ SDS as the running buffer. Gels were stained with Coomassie solution $[0.3 \%$ Coomassie $R-250, \mathrm{w} / \mathrm{v}, 45 \%$ methanol, v/v, and $10 \%$ acetic acid, $\mathrm{v} / \mathrm{v}$, dissolved in double-distilled water
$\left.\left(\mathrm{ddH}_{2} \mathrm{O}\right)\right]$ for $60 \mathrm{~min}$ and washed several times for $30 \mathrm{~min}$ with destaining solution (20\% methanol, v/v, and $10 \%$ acetic acid, v/v, dissolved in $\mathrm{ddH}_{2} \mathrm{O}$ ) until protein bands were satisfactorily visualized.

Protein cross-linking: To check the oligomerization state of the CPC polypeptides after anion-exchange disuccinimidyl suberate linker (Thermo Scientific, Waltham, MA, USA) was added to purified CPC to a final concentration of $5 \mathrm{mM}$ (in $50 \mathrm{mM}$ sodium phosphate buffer, $\mathrm{pH}$ 7). Samples were subsequently incubated at room temperature for a total of $40 \mathrm{~min}$ after which the reaction was quenched by addition of Tris- $\mathrm{HCl}(\mathrm{pH} 8)$ to a final concentration of $50 \mathrm{mM}$. Samples were then analyzed by SDS-PAGE.

Mass spectrometry analysis: Protein bands were carefully excised from polyacrylamide gels, washed 3 times with nanopure $\mathrm{H}_{2} \mathrm{O}$ for $30 \mathrm{~min}$ at room temperature and had the Coomassie staining removed with $0.2 \mathrm{M}$ ammonium bicarbonate in $50 \%$ acetonitrile $(\mathrm{v} / \mathrm{v})$ for $30 \mathrm{~min}$ at $37^{\circ} \mathrm{C}$. Bands were then incubated with $10 \mathrm{mM}$ dithiothreitol (in $0.2 \mathrm{M}$ ammonium bicarbonate solution) for $30 \mathrm{~min}$ at $37^{\circ} \mathrm{C}$, alkylated with $55 \mathrm{mM}$ iodoacetamide (in $0.2 \mathrm{M}$ ammonium bicarbonate solution) for $30 \mathrm{~min}$ at $37^{\circ} \mathrm{C}$ in the dark, dehydrated with acetonitrile, dried at room temperature for $10 \mathrm{~min}$, and placed at $4^{\circ} \mathrm{C}$. Subsequently, proteolysis buffer $(50 \mathrm{mM}$ ammonium bicarbonate, $10 \%$ acetonitrile, v/v, and $0.042 \mu \mathrm{g} \mu \mathrm{L}^{-1}$ trypsine) was added and samples were incubated for $45 \mathrm{~min}$ at $4^{\circ} \mathrm{C}$. More buffer (without trypsine) was added to submerge the bands and samples were left overnight at $37^{\circ} \mathrm{C}$. The supernatant was recovered and two additional extractions were performed, once with $60 \%$ acetonitrile (v/v) and $1 \%$ formic acid (v/v), and once with $100 \%$ acetonitrile. The supernatant and extracts were pooled and dried at room temperature in a SpeedVac (Savant Instruments Inc., Farmingdale, NY, USA).

Samples were analyzed in a $\alpha$-cyano-4-hydroxycinnamic acid matrix $\left[10 \mathrm{mg} \mathrm{mL} \mathrm{mL}^{-1}\right.$ in $50 \%$ acetonitrile containing $0.1 \%$ formic acid $(\mathrm{v} / \mathrm{v})$, further referred to as CHCA matrix], and additionally in a CHCA matrix containing isopropanol $\left(10 \mathrm{mg} \mathrm{mL}^{-1}\right.$ in isopropanol and $0.1 \%$ formic acid, $\mathrm{v} / \mathrm{v}$, further referred to as CHCA+IP matrix), on a MALDI-TOF Microflex (Bruker Daltonics Inc., Billerica, MA, USA) mass spectrometer in the positive ion mode. Final spectra are the sum of 450 random laser hits (15 runs, 30 hits per run) per sample.

The program mMass version 5.5.0 (Strohalm et al. 2008, 2010; Niedermeyer and Strohalm 2012) was used to analyze the spectra and the MALDI-TOF Peptides algorithm was used to detect $\mathrm{m} / \mathrm{z}$ monoisotopic signals considering the following parameters: signal to noise ratio 3.5 and a relative intensity limit of $0.2 \%$. The Mascott $P M F$ tool then identified the samples based on the detected monoisotopic signals according to the following parameters: database, $N C B I$; proteolysis enzyme, trypsine; missed cuts, 1; fixed modifications, carbamidomethylation (alkylation with iodoacetamide); variable modification, methionine oxidation; mass, monoisotopic; mass tolerance, 0.1-0.3 Da. Database searches were performed without any 
taxonomic restrictions and results were reported using a significance threshold of $p<0.05$ for protein identification. Hits for hypothetical and predicted proteins were not included in the final results. The raw mass spectrometry files are included in the supplemental data.

\section{Results}

PBS isolation via ultracentrifugation and spectral characterization: Aphanizomenon gracile PBSs were obtained by extraction with a high-ionic strength buffer, to avoid complex dissociation as described elsewhere (Gantt et al. 1979) and subsequent purification via ultracentrifugation on a sucrose gradient. After recovery of the PBSs from the gradient, absorption and fluorescence emission spectra were measured to assay the integrity of the PBSs. Spectral scanning showed that the PBSs absorbed maximally at $640 \mathrm{~nm}$ (Fig. 1A), a value in between the absorption maxima of CPC (620 nm) (Benedetti et al. 2006) and allophycocyanin (APC, $650 \mathrm{~nm}$ ) (Bryant et al. 1976) and indicative of the presence of both. When excited at $585 \mathrm{~nm}$, the PBSs showed a clear, single fluorescence emission peak at $670 \mathrm{~nm}$ that corresponds to the emission maximum of APC (670-680 nm, Fig. 1A) (MacColl 2004), which is the main energy acceptor in the PBS core from where the harvested energy is transferred to Chls in PSI and PSII. No fluorescence emission peak could be discerned at $650 \mathrm{~nm}$, the fluorescence maximum of CPC, which shows close proximity and correct organization of the CPC and APC units so that efficient energy transfer can occur between both and hence confirms the structural integrity of the isolated PBSs (Gantt et al. 1979). Besides CPC and APC, the presence of other phycobiliproteins, such as phycoerythrocyanins, which maximally absorb green light in the 540-580 $\mathrm{nm}$ region, could not be demonstrated.
SDS-PAGE analysis of PBS components: To further analyze PBS composition, total PBS proteins were separated via SDS-PAGE (Fig. 1B). Several bands with different intensities are resolved on the gel with two mayor bands in the $15-20 \mathrm{kDa}$ region that correspond to the alpha and beta subunit of the predominant phycobiliprotein CPC and also the alpha and beta subunit of APC that is very similar in size but present in lower quantities. Molecular mass values of both $\mathrm{CPC}$ subunits show good correlation with those reported in literature; $14-18 \mathrm{kDa}$ for the alpha and $15-20 \mathrm{kDa}$ for the beta subunit, respectively (MacColl 1998). The band corresponding to the alpha CPC subunit masks a second protein band of lower intensity and slightly lower molecular mass, as can be appreciated when less protein is loaded and the sample is rerun (Fig. 2A). This band most likely belongs to the alpha subunit of APC since it is absent in the purified CPC samples (Fig. $2 A$ ) and because its size of approximately $14 \mathrm{kDa}$ does not correlate with the size of that of known linker proteins, which are smaller $(<10 \mathrm{kDa})$ or larger $(>27 \mathrm{kDa})$ than $14 \mathrm{kDa}$ (Watanabe and Ikeuchi 2013).

The size of the band at $100 \mathrm{kDa}$ is in good accordance with that of the $\mathrm{L}_{\mathrm{CM}}$ protein that links the core to the membrane and also functions as a terminal acceptor, which transfers harvested light energy to the membrane-embedded PSI and PSII (Rusckowski and Zilinskas 1982, MacColl 2004, Chang et al. 2015). Two diffuse bands are visible at $50-60 \mathrm{kDa}$, that are similar in size to soluble elements of the photosynthetic redox reactions, such as ferredoxin $\mathrm{NADP}^{+}$reductase (FNR), that co-purified with PBSs in a previous study (Chang et al. 2015). The set of three bands around $30 \mathrm{kDa}$ correlates well with the sizes of the three rod linker proteins $(29-33.5 \mathrm{kDa})$ that organize rod cylinder structure (Watanabe and Ikeuchi 2013). These
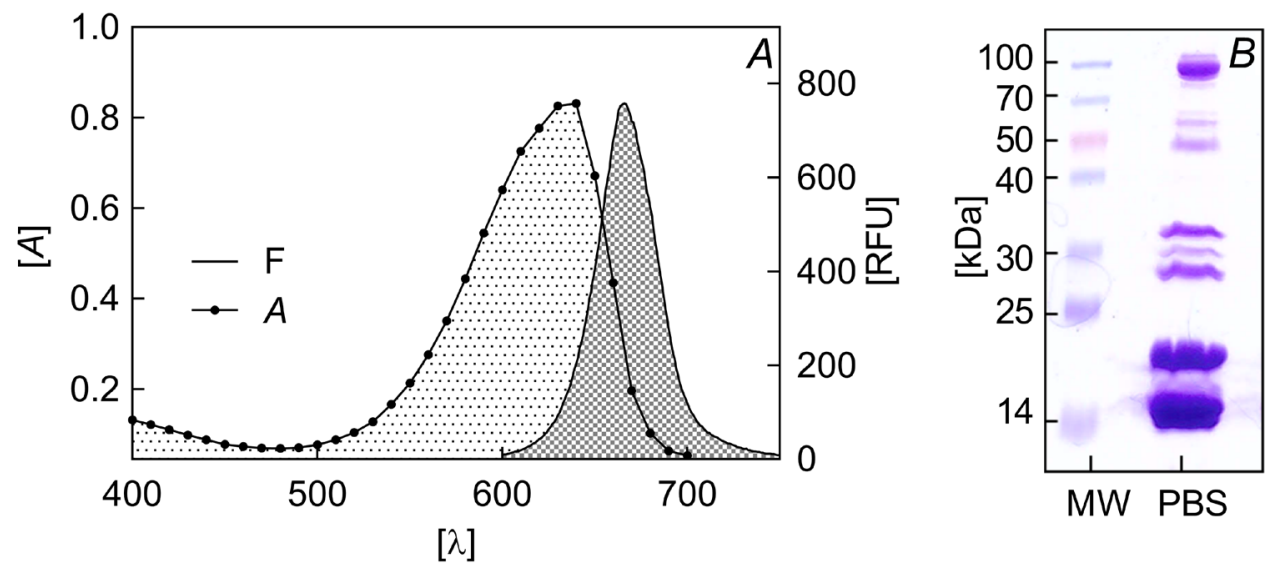

Fig. 1. Spectral characterization and SDS-PAGE analysis of isolated PBSs. (A) Absorption and emission spectra of purified PBSs suspended in $0.75 \mathrm{M}$ potassium phosphate buffer $\mathrm{pH} 7$ and measured at room temperature. Dotted line: Absorption spectrum showing a maximum at $640 \mathrm{~nm}$ in between the theoretical maxima of CPC $(620 \mathrm{~nm})$ and APC $(650 \mathrm{~nm})$. Absorbance was measured at 10-nm intervals. Full line: Fluorescence emission spectrum after excitation at $585 \mathrm{~nm}$ showing a maximum at $670 \mathrm{~nm}$ that is characteristic of APC. Emission was measured at 1-nm intervals with the excitation and emission slit widths set at $3 \mathrm{~nm}$. (B) SDS-analysis of purified PBSs on a $12 \%$ polyacrylamide gel. A total of $30 \mu \mathrm{g}$ protein was loaded. The molecular marker protein size is given in $\mathrm{kDa}$. Nine bands are resolved, some of which appear as doublets, possibly due to some degree of protein degradation during PBS extraction, purification, and sample handling. A - absorbance; F - fluorescence; MW - molecular mass marker; PBS - phycobilisome; RFU relative fluorescence units. 

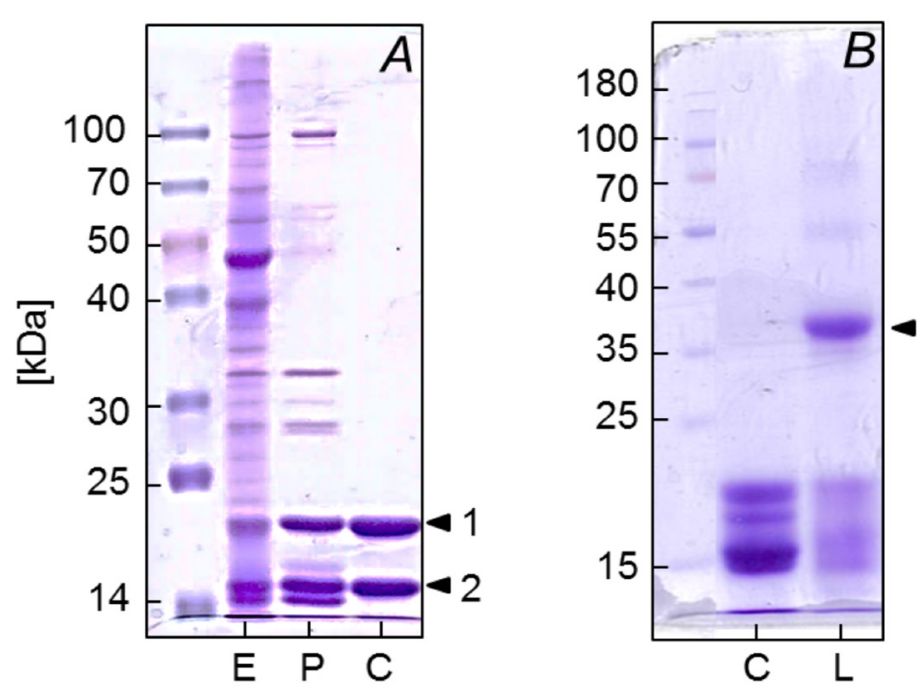

Fig. 2. (A) SDS-PAGE analysis of purified CPC (C), PBS (P), and crude cell extract (E). For each sample $5 \mu \mathrm{g}$ of total protein was loaded on a $12 \%$ gel. Note the visual absence of contaminating proteins in the lane with ultrapure CPC $\left(\mathrm{A}_{620} / \mathrm{A}_{280}>5\right)$. Both CPC polypeptide bands (numbered $1 \& 2$ and indicated with black arrows) were excised and subjected to mass spectrometry to further corroborate their identity. When $5 \mu \mathrm{g}$ of PBS is loaded on gel (instead of $30 \mu \mathrm{g}$, Fig. $1 B$ ) the lower band at around $15 \mathrm{kDa}$ is clearly resolved into two separate bands. (B) SDS-PAGE analysis of purified CPC before (C) and after cross-linking (L). For each sample $5 \mu \mathrm{g}$ of total protein was loaded on a $12 \%$ gel. After cross-linking one predominant oligomer is visible around $37 \mathrm{kDa}$ (black arrow) that corresponds to the $(\alpha \beta)$ monomer. Also some protein degradation is observed for both samples. C-C-phycocyanin; E-cell extract; L-crosslinked C-phycocyanin; $\mathrm{P}$ - phycobilisome. bind and organize the hexameric phycobiliprotein discs at the rod terminus $\left(\mathrm{L}_{\mathrm{T}}\right)$, at the central rod part $\left(\mathrm{L}_{\mathrm{R}}\right)$, and at the junction of the rod and core cylinders $\left(\mathrm{L}_{\mathrm{RC}}\right)$. Due to their low molecular mass, both the core linker protein $\left(\mathrm{L}_{\mathrm{C}}\right)$, involved in core cylinder structure organization, and $\mathrm{L}_{\mathrm{T}}$ that caps the rod cylinders and is very similar in size to $\mathrm{L}_{\mathrm{C}}(\sim 8$ and $9 \mathrm{kDa}$, respectively, MacColl 1998), are not resolved on this gel.

CPC purification: A two-step purification protocol was developed to obtain pure CPC. First, cells were extracted with acidic, low-ionic strength buffer and samples run on a size-exclusion column to desalt and separate small molecular mass species from the phycobiliproteins that eluted near the void volume. The blue fractions were then

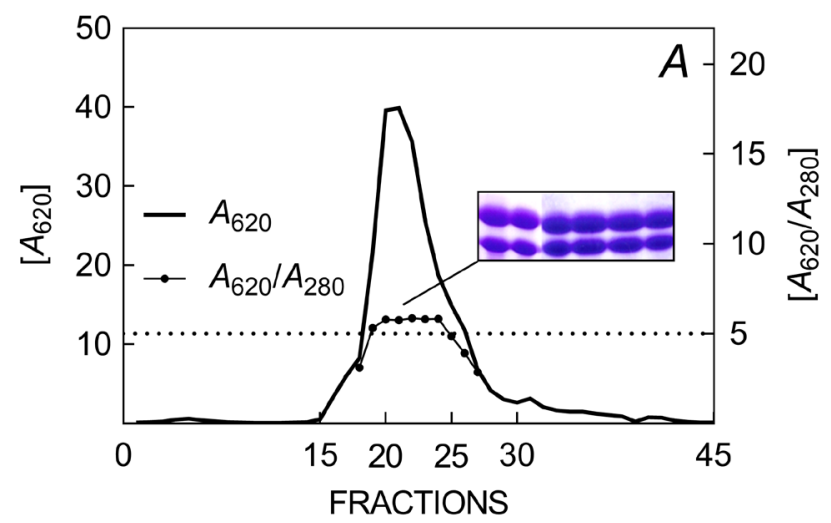

pooled, loaded on an anion-exchange column, and eluted with a linear gradient of 5-100 mM sodium phosphate buffer to separate CPC from APC, linker proteins, and other contaminating proteins (Fig. $3 A$ ). The ratio of $\mathrm{A}_{620} / \mathrm{A}_{280}$ was used as a measure of CPC purity where $\mathrm{A}_{620} / \mathrm{A}_{280}$ values smaller than or equal to 0.7 and 3.9 correspond to food and reactive grade $\mathrm{CPC}$, while analytical grade CPC has $\mathrm{A}_{620} / \mathrm{A}_{280}$ values of 4 or higher (Rito-Palomares et al. 2001). After anion-exchange chromatography, the eluted CPC fractions were assayed on gel and a total of six ultrapure fractions with $\mathrm{A}_{620} / \mathrm{A}_{280}$ values higher than 5 (5.3-5.8), for which no contaminating protein bands were visible (Fig. 2S, supplement), were pooled and stored for further analysis.

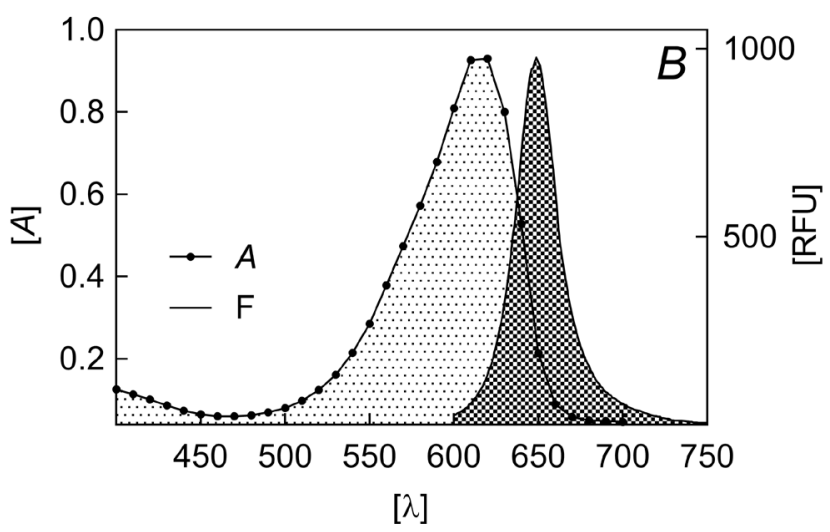

Fig. 3. CPC anion-exchange chromatography and CPC spectral characterization. $(A)$ The elution profile of purified CPC after anionexchange chromatography (developed with a linear gradient of 5-100 $\mathrm{mM}$ sodium phosphate). The presence of CPC in the collected fractions was monitored at $620 \mathrm{~nm}$, the wavelength at which CPC shows maximal absorption. CPC purity is measured by the ratio of the $\mathrm{A}_{620}$ and $\mathrm{A}_{280}$, so for the fractions that contain the bulk CPC the $\mathrm{A}_{280}$ was also determined. Ultrapure fractions with $\mathrm{A}_{620} / \mathrm{A}_{280}>5$ were pooled and stocked at $-20^{\circ} \mathrm{C}$. Boxed inset: SDS-PAGE analysis of the individual ultrapure fractions (for the full image see Fig. 2S). Horizontal dotted line: threshold for ultrapure fractions $\left(\mathrm{A}_{620} / \mathrm{A}_{280}\right.$ equal to or higher than 5$)$. $(B)$ Absorption and emission spectra of purified CPC suspended in $0.05 \mathrm{M}$ sodium phosphate buffer $\mathrm{pH} 7$ and measured at room temperature. Analytical grade CPC $\left(\mathrm{A}_{620} / \mathrm{A}_{280}>5\right)$, obtained via size-exclusion and anion-exchange chromatography, was assayed to determine its spectral characteristics. The absorption maximum and fluorescence emission maximum are 620 and $650 \mathrm{~nm}$, respectively. Absorbance was measured at 10-nm intervals. Fluorescence emission after excitation at $585 \mathrm{~nm}$ was measured at 1-nm intervals with the excitation and emission slit widths set at $3 \mathrm{~nm}$. A - absorbance; $A_{280}$ - absorbance at $280 \mathrm{~nm} ; \mathrm{A}_{620}$ - absorbance at $620 \mathrm{~nm} ; \mathrm{CPC}$ - C-phycocyanin; F - fluorescence; $\mathrm{RFU}$ - relative fluorescence units; $\lambda$ - wavelength. 
CPC polypeptide oligomerization: The CPC alpha and beta polypeptide associate into $(\alpha \beta)$ mono-, di-, tri- and hexamers, depending on the ionic strength and the conditions of the buffer in which they are suspended. An ionic strength of $0.75-1 \mathrm{M}$ is required to maintain the PBS superstructure (Gantt et al. 1979) and since the main peak of CPC eluted from the anion-exchange column at $40-50 \mathrm{mM}$ (Fig. 3A), it is likely that the CPC in these fractions has dissociated into one or several polypeptide multimers. To assay the latter, the purified CPC was cross-linked and run on gel (Fig. 2B). This revealed a predominant band at $\sim 37 \mathrm{kDa}$ that corresponds to the $(\alpha \beta)$ monomer and is almost identical in size to the value reported by Bhat and Madyastha (2000) for the CPC monomer of Arthrospira platensis $(37.5 \mathrm{kDa})$. CPC purified by this method is thus present in its monomeric state.

CPC spectral characterization and mass spectrometry: The absorption and fluorescence emission spectra of the purified CPC were measured and showed clear maxima at $620 \mathrm{~nm}$ and $650 \mathrm{~nm}$, respectively (Fig. $3 B$ ). These values coincide with those reported earlier for CPC from other cyanobacterial species $\left(\lambda_{\max }=610-620 \mathrm{~nm}, E_{\max }=650 \mathrm{~nm}\right)$ (Glazer and Cohen-Bazire 1971, Bryant et al. 1976, Boussiba and Richmond 1979, Benedetti et al. 2006). The CPC was then separated on gel and the two visualized polypeptide bands analyzed via PMF mass spectrometry to further characterize these components (Fig 2A, Table 1). This confirmed their identity as being the CPC alpha and beta polypeptide. Using the same stringency conditions for inclusion in the results (a significance threshold of $p<0.05$ ), also an ABC transporter ATP-binding protein and LIV-I protein $\mathrm{F}$ were detected for the beta polypeptide sample when $\mathrm{CHCA}+\mathrm{IP}$, but not $\mathrm{CHCA}$, was used as a matrix. However, both these proteins have an estimated mass of $\sim 26 \mathrm{kDa}$ that does not correspond to that of the excised beta polypeptide band $(\sim 20 \mathrm{kDa})$. Moreover, they belong to Achromobacter, a gram-negative bacterium, and not to $A$. gracile or any other related cyanobacterial species. Therefore the identification of the ABC transporter ATPbinding protein and LIV-I protein $\mathrm{F}$ in the beta polypeptide sample with $\mathrm{CHCA}+\mathrm{IP}$ matrix was considered as nonrelevant.

\section{Discussion}

The aim of this study was twofold, one goal was to isolate and characterize the PBS of the freshwater cyanobacterium A. gracile, for which a detailed study of its PBS lightharvesting apparatus had not been reported before. A second objective was to purify its CPC that is of interest because phycobiliproteins, due to the peculiar structure of their chromophores, are potent radical scavengers and antioxidants with pharmaceutical value as such (Benedetti et al. 2010, Liu et al. 2016).

The PBS easily dissociates into its constituting phycobiliproteins and in solution these are often found as their monomers, trimers or hexamers instead of being complexed with linker proteins in the PBS super structure (Füglistaller et al. 1987, MacColl 2004, Singh et al. 2015). Care was thus taken to extract intact PBSs with a high-ionic strength buffer, crucial to conserve the PBS structure, and purify these from contaminating proteins via ultracentrifugation on a sucrose gradient (Gantt et al. 1979). The integrity of the isolated PBSs was assayed measuring the absorption and fluorescence emission spectra. The absorption maximum at $640 \mathrm{~nm}$, in between that of CPC $(620 \mathrm{~nm})$ and APC $(650 \mathrm{~nm})$, indicated the presence of both these phycobiliproteins. This is a prerequisite for correct structure given that the basic PBS structure consists of core cylinders built from APC discs that support protruding rod cylinders made up from CPC discs, all held together by linker proteins (MacColl 1998, Singh et al. 2015).

In the rod cylinders, however, different arrangements of phycobiliproteins can exist (Glazer 1985, 1994; MacColl

Table 1. Mass spectrometry analysis of the two polypeptide chains from the purified CPC. Peptide Mass Fingerprinting confirmed the identity $(p<0.05)$ of both peptides as the alpha and beta CPC subunit. Analysis also picked up some transporter related protein when $\mathrm{CHCA}+\mathrm{IP}$, but not CHCA, was used as the matrix for sample ionization, but these are considered nonrelevant as explained in the text. See Figs. 3S-6S (supplement) for the corresponding spectra.

\begin{tabular}{lll}
\hline Sample & Matrix & Matches \\
\hline 1 & CHCA & Phycocyanin subunit beta [Nostocales] \\
& Phycocyanin [Anabaena sp. AL93] \\
& CHCA+IP & Phycocyanin subunit beta [Nostocales] \\
& Phycocyanin [Anabaena sp. AL93] \\
& ABC transporter ATP-binding protein [Achromobacter] \\
& Branched-chain amino acid transport ATP-binding protein LivF [Achromobacter xylosoxidans] \\
& LIV-I protein F [Achromobacter sp. 2789STDY5608628] \\
& ABC transporter ATP-binding protein [Achromobacter xylosoxidans] \\
& ABC transporter ATP-binding protein [Achromobacter ruhlandii] \\
& C-phycocyanin alpha subunit, partial [Aphanizomenon sp. 14E6] \\
& C-phycocyanin alpha subunit, partial [Aphanizomenon sp. 14E6] \\
& Phycocyanin alpha subunit, partial [Aphanizomenon gracile AB200/32] \\
& Phycocyanin alpha subunit, partial [Aphanizomenon gracile AB200/06]
\end{tabular}


1998, Watanabe and Ikeuchi 2013, Ledermann et al. 2017, Rexroth et al. 2017). Whereas the most basic rod cylinders exclusively contain CPC, more complex PBSs have rod cylinders that complement $\mathrm{CPC}$ discs at the coreproximal end with phycoerythrin discs at the core-distal end. Some species can also vary their rod phycobiliprotein composition in function of the light quality in their environment, a process known as chromatic adaptation (Glazer 1994). When these organisms are grown under cool white fluorescent light, which has a strong green component, they produce phycoerythrins to absorb across the green range and complement the CPC and APC that absorb reddish light (Bennett 1973). Cool white fluorescent light was used in this study to illuminate the cultures so the presence of phycoerythrins in the PBS could be possible. However, the absorption spectrum of the isolated PBSs did not show the characteristic shoulder peak at 540-570 $\mathrm{nm}$ that is typical for phycoerythrins and this suggests that A. gracile is not capable of chromatic adaptation, although more experimentation is required to corroborate this finding.

The integrity of the PBSs was further confirmed by the fluorescence emission spectrum. In intact PBSs energy from photons captured by the rods is funneled to APC in the core from where it is transferred to the reaction centers Chls of the photosystems. Upon excitation of such a PBS only the last element in the energy transfer chain shows fluorescence and indeed, the emission maximum at $670 \mathrm{~nm}$ observed in the fluorescence spectrum corresponds to emission of APC present in the core, while no peak characteristic for CPC at $650 \mathrm{~nm}$ could be detected. This demonstrates good energetic coupling between the CPC rods and APC core and overall correct PBS structure.

Upon confirmation of PBS integrity, total PBS proteins were analyzed via SDS-PAGE to dissect the individual protein constituents of the PBS. The distinctive protein pattern visualized on gel was similar to that of other PBSs and based on their molecular mass, the bands were assigned to the different linker proteins and to the alpha and beta polypeptides of the CPC and APC phycobiliproteins. Also FNR was detected and, rather than being a contaminant, most likely co-purified because of close association with the PBS where it might function in redox reactions (Singh et al. 2015). Indeed, some cyanobacterial PBSs can carry a distally bound FNR to assist in the conversion of captured energy to chemical energy by catalyzing the reduction of $\mathrm{NADP}^{+}$to NADPH, which is the final reaction of the linear photosynthetic electron chain (Morsy et al. 2008).

To purify CPC, a protocol was designed to dissociate the PBS and separate the CPC from APC and the linker proteins. Hereto cells were extracted with a low-ionic strength buffer that promotes PBS dissociation, after which the CPC was recovered via two chromatographic steps. First the extract was subjected to size-exclusion chromatography to further reduce its ionic strength and to concentrate the CPC close to the void volume. Then total phycobiliproteins, which are acidic of nature (Glazer 1988), were captured by anion-exchange chromatography and separated from the basic linker proteins. Finally, a phosphate gradient up to $0.1 \mathrm{M}$ was applied to specifically elute CPC, while APC that elutes close to $0.2 \mathrm{M}$ (Glazer 1988) was retained on the column.

The purity of the CPC was assessed by its ratio of $\mathrm{A}_{620} / \mathrm{A}_{280}$ and on gel. For several of the fractions containing the bulk of the CPC $\mathrm{A}_{620} / \mathrm{A}_{280}$ values higher than 5 were reached, where CPC with a value of 4 or higher is considered analytical grade (Rito-Palomares et al. 2001). These fractions contained very pure CPC for which no contaminating protein bands were present on gel and were pooled. The spectra of this CPC show clear absorption and emission maxima, 620 and $650 \mathrm{~nm}$, respectively, that coincide with those reported previously for CPC from different species (Benedetti et al. 2006, Sonani et al. 2014). When the spectra of CPC are compared to those of the PBS, a shift in maxima can be observed, from 640 to $620 \mathrm{~nm}$ for the absorption maximum and from 670 to $650 \mathrm{~nm}$ for the fluorescence maximum, which is due to the loss of the APC during the purification procedure. Extensive mass spectrometry analysis further confirmed CPC alpha and beta polypeptide identity. CPC purified by this method is completely dissociated into its basic building block, the $(\alpha \beta)$ monomer. Taken together, these results show that analytical grade CPC can be easily obtained from $A$. gracile following this straightforward two-step purification protocol. Commercial CPC or extracts enriched with CPC are mainly derived from Arthrospira (formerly Spirulina) species and Aphanizomenon flos-aquae that are both grown in open-pond systems and lakes which are prone to contamination with undesired microorganisms. In contrast, $A$. gracile is easily cultivated in bioreactors where strict control can avoid the latter.

In conclusion, this study showed in details the isolation and characterization of both the PBS and CPC from A. gracile. The overall protein composition of the PBS consists of phycobiliproteins and linker proteins. Both the phycobiliproteins CPC andAPC were present in the PBS, but not phycoerythrin, suggesting that $A$. gracile is not capable of chromatic adaptation. All linkers described in literature $\left(\mathrm{L}_{\mathrm{T}}, \mathrm{L}_{\mathrm{R}}, \mathrm{L}_{\mathrm{RC}}, \mathrm{L}_{\mathrm{C}}\right.$, and $\mathrm{L}_{\mathrm{CM}}$ ) were identified on gel, except for $\mathrm{L}_{\mathrm{T}}$ and $\mathrm{L}_{\mathrm{R}}$ that were not resolved due to their small size. The results showed that the PBS adheres to the general rule for PBSs, namely that these are made up of phycobiliproteins held together by the classic set of linker proteins. Both the protein composition and spectral characteristics of the A. gracile PBS are in good accordance with those reported for PBSs from other cyanobacteria. In a second line of work, the mayor phycobiliprotein CPC was extracted and processed to an analytical grade product. The relative ease of the purification protocol and high purity of the product obtained suggest that $A$. gracile can be used as an alternative source of CPC for nutraceutical or pharmaceutical purposes. This study, to our best knowledge, is the first to report the purification and characterization of the PBS and CPC of the freshwater diazotrophic cyanobacterium A. gracile. 


\section{References}

Benedetti S., Benvenuti F., Pagliarani S. et al.: Antioxidant properties of a novel phycocyanin extract from the blue-green alga Aphanizomenon flos-aquae. - Life Sci. 75: 2353-2362, 2004.

Benedetti S., Benvenuti F., Scoglio S., Canestrari F.: Oxygen radical absorbance capacity of phycocyanin and phycocyanobilin from the food supplement Aphanizomenon flos-aquae.J. Med. Food 13: 223-227, 2010.

Benedetti S., Rinalducci S., Benvenuti F. et al.: Purification and characterization of phycocyanin from the blue-green alga Aphanizomenon flos-aquae. - J. Chromatogr. B 833: 12-18, 2006.

Bennett A.: Complementary chromatic adaptation in a filamentous blue-green alga. - J. Cell Biol. 58: 419-435, 1973.

Bhat V.B., Madyastha K.M.: C-phycocyanin: a potent radical scavenger in vivo and in vitro. - Biochem. Bioph. Res. Co. 275: $20-25,2000$.

Blankenship R.E.: How Cyanobacteria went green. - Science 355: 1372-1373, 2017.

Boussiba S., Richmond A.E.: Isolation and characterization of phycocyanins from the blue-green alga Spirulina platensis. Arch. Microbiol. 120: 155-159, 1979.

Bryant D.A., Glazer A.N., Eiserling F.A.: Characterization and structural properties of the major biliproteins of Anabaena sp.Arch. Microbiol. 110: 61-75, 1976.

Chang L., Liu X., Li Y. et al.: Structural organization of an intact phycobilisome and its association with photosystem II. - Cell Res. 25: 726-737, 2015.

de Marsac N.T., Cohen-Bazire G.: Molecular composition of cyanobacterial phycobilisomes. - P. Natl. Acad. Sci. USA 74: 1635-1639, 1977.

Ducret A., Sidler W., Wehrli E. et al.: Isolation, characterization and electron microscopy analysis of a hemidiscoidal phycobilisome type from the cyanobacterium Anabaena sp. PCC 7120. - Eur. J. Biochem. 236: 1010-1024, 1996.

Fernandes e Silva E., da Silva Figueira F., Portantiolo Lettnin A. et al.: C-Phycocyanin: Cellular targets, mechanisms of action and multi drug resistance in cancer. - Pharmacol. Rep. 70: 75-80, 2018.

Füglistaller P., Mimuro M., Suter F., Zuber H.: Allophycocyanin complexes of the phycobilisome from Mastigocladus laminosus. Influence of the linker polypeptide LC8.9 on the spectral properties of the phycobiliprotein subunits. - Biol. Chem. H.-S. 368: 353-367, 1987.

Gantt E., Lipschultz C.A., Grabowski J., Zimmerman B.K.: Phycobilisomes from blue-green and red algae: isolation criteria and dissociation characteristics. - Plant. Physiol. 63: 615-620, 1979

Glazer A.N.: Light harvesting by phycobilisomes. - Annu. Rev. Biophys. Bio. 14: 47-77, 1985.

Glazer A.N.: Adaptive variations in phycobilisome structure. In: Bittar E.E., Barber J. (ed.): Advances in Molecular and Cell Biology. Molecular Processes of Photosynthesis. Pp. 119-149. Elsevier 1994

GlazerA.N.: Phycobiliproteins. - Method.Enzymol 167:291-303, 1988.

Glazer A.N., Cohen-Bazire G.: Subunit structure of the phycobiliproteins of blue-green algae. - P. Natl. Acad. Sci. USA 68: 1398-1401, 1971.

Jensen G., Attridge V., Carter S.G. et al: Consumption of an aqueous cyanophyta extract derived from Arthrospira platensis is associated with reduction of chronic pain: results from two human clinical pilot studies. - Nutr. Diet. Suppl. 8: $65-70,2016$.
Komárek J.: [Freshwater Flora of Central Europe, Vol. 19/3: Cyanoprokaryota: 3rd part: Heterocytous Genera.] Pp. 1131. Springer Spektrum, Berlin-Heidelberg 2013. [In German]

Komárek J., Komárková J.: Diversity of Aphanizomenon-like cyanobacteria. - Czech Phycol. 6: 1-32, 2006.

Ledermann B., Aras M., Frankenberg-Dinkel N.: Biosynthesis of cyanobacterial light-harvesting pigments and their assembly into phycobiliproteins. - In: Hallenbeck P.C. (ed.): Modern Topics in the Phototrophic Prokaryotes: Metabolism, Bioenergetics, and Omics. Pp. 305-340. Springer International Publishing, Cham 2017.

Liu H., Zhang H., Niedzwiedzki D.M. et al.: Phycobilisomes supply excitations to both photosystems in a megacomplex in cyanobacteria. - Science 342: 1104-1107, 2013.

Liu Q., Huang Y., Zhang R. et al.: Medical application of Spirulina platensis derived C-phycocyanin. - Evid.-Based Compl. Alt. 2016: 7803846, 2016.

MacColl R.: Cyanobacterial phycobilisomes. - J. Struct. Biol. 124: 311-334, 1998.

MacColl R.: Allophycocyanin and energy transfer. - BBA-Bioenergetics 1657: 73-81, 2004.

Morsy F.M., Nakajima M., Yoshida T. et al: Subcellular localization of ferredoxin-NADP ${ }^{+}$oxidoreductase in phycobilisome retaining oxygenic photosynthetic organisms. Photosynth. Res. 95: 73-85, 2008.

Niedermeyer T.H.J., Strohalm M.: mMass as a software tool for the annotation of cyclic peptide tandem mass spectra. - PLoS ONE 7: e44913, 2012.

Peng P.-P., Dong L.-L., Sun Y.-F. et al.: The structure of allophycocyanin B from Synechocystis PCC 6803 reveals the structural basis for the extreme redshift of the terminal emitter in phycobilisomes. - Acta Crystallogr. D 70: 2558-2569, 2014.

Pereira P., Li R., Carmichael W. et al.: Taxonomy and production of paralytic shellfish toxins by the freshwater cyanobacterium Aphanizomenon gracile LMECYA40. - Eur. J. Phycol. 39: 361-368, 2014.

Rexroth S., Nowaczyk M.M., Rögner M.: Cyanobacterial photosynthesis: The light reactions. - In: Hallenbeck P. (ed.): Modern Topics in the Phototrophic Prokaryotes. Pp. 163-191. Springer, Cham 2017.

Rito-Palomares M., Nuñez L., Amador D.: Practical application of aqueous two-phase systems for the development of a prototype process for c-phycocyanin recovery from Spirulina maxima. - J. Chem. Technol. Biot. 76: 1273-1280, 2001.

Rusckowski M., Zilinskas B.A.: Allophycocyanin I and the 95 kilodalton polypeptide: The bridge between phycobilisomes and membranes. - Plant. Physiol. 70: 1055-1059, 1982.

Scoglio S., Benedetti Y., Benvenuti F. et al.: Selective monoamine oxidase B inhibition by an Aphanizomenon flos-aquae extract and by its constitutive active principles phycocyanin and mycosporine-like amino acids. - Phytomedicine 21: 992-997, 2014.

Singh N.K., Sonani R.R., Rastogi R.P., Madamwar D.: The phycobilisomes: an early requisite for efficient photosynthesis in cyanobacteria. - EXCLI J. 14: 268-289, 2015.

Sonani R.R., Singh N.K., Kumar J. et al.: Concurrent purification and antioxidant activity of phycobiliproteins from Lyngbya sp. A09DM: An antioxidant and anti-aging potential of phycoerythrin in Caenorhabditis elegans. - Process Biochem. 49: 1757-1766, 2014.

Stadnichuk I.N.: Phycobiliproteins: Determination of chromophore composition and content. - Phytochem. Analysis 6: 281-288, 1995.

Strohalm M., Hassman M., Košata B., Kodíček M.: mMass data miner: an open source alternative for mass spectrometric data 
analysis. - Rapid Commun. Mass Sp. 22: 905-908, 2008.

Strohalm M., Kavan D., Novák P. et al.: mMass 3: A crossplatform software environment for precise analysis of mass spectrometric data. - Anal. Chem. 82: 4648-4651, 2010.
Watanabe M., Ikeuchi M.: Phycobilisome: architecture of a lightharvesting supercomplex. - Photosynth. Res. 116: 265-276, 2013.

(C) The authors. This is an open access article distributed under the terms of the Creative Commons BY-NC-ND Licence. 